\section{O ENSINO DA EDUCAÇÃO FÍSICA NA EJA: UMA ANÁLISE A PARTIR DE FALAS DOS PROFESSORES}

\author{
PHYSICAL EDUCATION TEACHING AT EJA: AN ANALYSIS FROM \\ TEACHERS'PRACTICES P
}

LA ENSEÑANZA DE EDUCACIÓN FÍSICA EN LA EJA: UN ANÁLISIS DE LOS DISCURSOS DE LOS PROFESORES C P

doi) https://doi.org/10.22456/1982-8918.112519

\section{Sérgio Henrique Noblat de Andrade Júnior*} <sergio.ipojuca@gmail.com>

(D) Agostinho da Silva Rosas** <agostinho.rosas@upe.br>

(D) Ana Rita Lorenzini** <ana.lorenzini@upe.br>

(iD) Lívia Tenorio Brasileiro** <livia.brasileiro@upe.br>

Marcílio Barbosa Mendonça de Souza Júnior** <marcilio.souza@upe.br>

Marcelo Soares Tavares de Melo**<marcelo.melo@upe.br>

\footnotetext{
*Prefeitura Municipal do Ipojuca. Ipojuca, PE, Brasil.

**Universidade de Pernambuco. Recife, PE, Brasil.
}

Recebido em: 27 mar. 2021 Aprovado em: 22 out. 2021 Publicado em: 28 dez. 2021

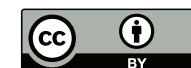

Este é um artigo publicado sob a licença Creative Commons Atribuição 4.0 Internacional (CC BY 4.0).

eISSN: $1982-8918$ 


\section{INTRODUÇÃO}

Este texto é um recorte de uma pesquisa dissertativa que teve por objetivo analisar o ensino da Educação Física no contexto da Educação de Jovens e Adultos (EJA) da rede municipal de ensino da Prefeitura do Ipojuca/PE, a partir de falas dos professores que ministram aulas na EJA. Município este que motivou a realização da pesquisa, devido à atividade profissional estar relacionada à formação de professores na EJA.

O Ensino da Educação Física (EF) na EJA é um desafio devido à sua diversidade, com características próprias e peculiaridades que a configuram como uma modalidade da educação básica, existente na Lei de Diretrizes e Bases da Educação Nacional - LDBEN (BRASIL, 2017a). Entretanto, Arroyo (2017) compreende a EJA como lócus de diversidade de tempos-espaços de formação das pessoas jovens e adultas e que se realiza em escolas, comunidades, igrejas, movimentos sociais, diversidade de sujeitos - do jovem ao idoso - não limitando apenas a estruturas escolarizadas.

A preocupação com a educação de adultos emerge no Brasil desde o período colonial, pautada por uma concepção catequista e formação de mão de obra nativa para o trabalho, a partir da chegada dos jesuítas no país (BEISIGEL, 2004; PAIVA, 2002; HADDAD; DI PIERRO, 2000).

$\mathrm{Na}$ história da educação de jovens e adultos, no contexto educacional brasileiro, ocorreram iniciativas que emergiram na busca por uma concepção crítica e reflexiva do processo de alfabetização dos adultos, pautada em ideais progressistas, libertadores, assim como a partir de um processo tecnicista e aligeirado, visando à manutenção do status quo. ${ }^{1}$

$\mathrm{Na}$ busca pelo efetivo direito à educação, a Lei de Diretrizes e Bases da Educação Nacional (BRASIL, 2017a), o Parecer n 11/2000 (BRASIL, 2000) e as Diretrizes Curriculares para Educação Básica (BRASIL, 2001, 2013b) trouxeram contribuições para a EJA a partir de princípios orientadores desenvolvidos na escola, nos componentes curriculares e na prática pedagógica dos professores, requerendo uma abordagem específica para o processo de ensino-aprendizagem na EJA.

Nessa modalidade da educação, percebemos que a EF esteve, ao longo da história brasileira, em segundo plano, haja vista a presença de prerrogativas legais ${ }^{2}$ que dificultam seu ensino, sua materialização e a formação inicial de professores.

\footnotetext{
1 Strelhow (2010) apresenta um panorama acerca da trajetória da EJA no Brasil, as iniciativas populares, a saber: "Movimento de Educação de Base" (1961-CNBB), Movimento de Cultura Popular do Recife 1961), Centros Populares de Cultura (UNE), Campanha de Pé no chão Também se Aprende a Ler (Prefeitura de Natal), Campanha de Educação Popular da Paraíba (CEPLAR, 1965); enquanto o movimento tecnicista e governamental: Cruzada Ação Básica Cristã (ABC-Recife, 1967), Movimento Brasileiro de Alfabetização (MOBRAL,1985), Fundação EDUCAR, 1990), Programa Nacional de Alfabetização (1998), Pronera (Programa Nacional de Educação na Reforma Agrária, 1998), Programa Brasil Alfabetizado (2003); proposta de coparticipação dos sujeitos alfabetizando e o poder público: Movimento de Alfabetização (Mova, 1996).

2 "A educação física, integrada à proposta pedagógica da escola, é componente curricular obrigatório da educação infantil e do ensino fundamental, sendo sua prática facultativa ao aluno: I - que cumpra jornada de trabalho igual ou superior a seis horas; II - maior de trinta anos de idade (grifo nosso); III - que estiver prestando serviço militar inicial ou que, em situação similar, estiver obrigado à prática da educação física; IV - amparado pelo Decreto-Lei no 1.044, de 21 de outubro de 1969; V - (vetado); VI - que tenha prole" (BRASIL, 2017, p.20).
} 
Apesar disso, essa barreira vem sendo paulatinamente reduzida por meio de propostas curriculares que estão sendo produzidas acerca da especificidade da EF na $\mathrm{EJA}^{3}$, possibilitando sua presença e organização teórico-metodológica.

Nesse sentido, em 2013 foram produzidos os Parâmetros Curriculares para a Educação Básica do Estado de Pernambuco (PCPE) com um documento específico para a EF no Ensino Fundamental, Ensino Médio e EJA (PERNAMBUCO, 2013a). São documentos tomando como referência a Cultura Corporal como objeto da EF, apresentando seus conteúdos e a sistematização do conhecimento com base na perspectiva Crítico-Superadora que tem como eixos temáticos: jogo, dança, luta, ginástica e esporte. Tal parâmetro apresenta-se a partir do conceito de expectativas de aprendizagem e anos de escolarização, explicitando sua avaliação e tecendo considerações sobre a inclusão na Educação Física Escolar.

Além disso, ao longo dos anos, vêm sendo desenvolvidos estudos tais como os de Franchi e Günther (2018), Günther (2014), Oliveira, Sousa e Melo (2015), Reis e Molina Neto (2014), Reis (2011), Martins (2019), os quais têm somado contribuições a partir de temáticas relacionadas: juvenilização da EJA, educação enquanto direito; experiência a partir do estágio supervisionado, na prática pedagógica e no âmbito do currículo cultural.

A produção de conhecimento sobre a EF na EJA contribui para o desenvolvimento da área, possibilitando a elaboração de estudos que tenham a EJA como centralidade, fornecendo elementos teórico-metodológicos para sua reflexão, materialização e sistematização na prática pedagógica, bem como implantação de proposta curricular específica.

Nesta pesquisa, defendemos que o ensino da EF na EJA precisa ser compreendido, refletido e materializado, considerando as características ediversidades dos sujeitos, pois o processo de ensino-aprendizagem requer uma aproximação com a realidade concreta, solicitando um maior engajamento de pesquisadores, professores e estudantes em prol de pesquisas e propostas pedagógicas específicas da EF.

\section{DECISÕES METODOLÓGICAS}

Este estudo, de natureza qualitativa, contou com uma pesquisa bibliográfica (GIL, 2008) e de campo (MINAYO, 2016) para compreender, à luz do método hermenêutico-dialético (HABERMAS, 1987), as falas dos professores de EF no contexto da EJA da rede municipal de ensino do Ipojuca/PE.

Essa rede conta com 27 professores lotados nas unidades escolares. Destes, 13 ministram aulas na EJA. Após a aplicação do questionário exploratório, alegando motivos pessoais, cinco professores desistiram de continuar fazendo parte da pesquisa ${ }^{4}$, reduzindo o quantitativo para oito sujeitos.

3 Negreiros (2013) identificou a presença de sete propostas curriculares para EF na EJA no cenário nacional presentes nos Estados de Alagoas (2010), Amapá (2009), Distrito Federal (2010), Espírito Santo (2009), Goiás (2010), Sergipe (2007) e Tocantins (2008). 
Os critérios de inclusão para escolha dos professores foram: ser graduado em EF, ser professor efetivo e lecionar na modalidade da educação EJA. Sendo os excluídos os que não responderam o questionário exploratório; não se colocaram à disposição para a entrevista.

Diante disso, foram realizadas e, posteriormente, analisadas as entrevistas semiestruturadas a partir da técnica de análise de conteúdo categorial por temática (BARDIN, 2011). A referida técnica permitiu estruturar o estudo a partir de categorias empíricas e analíticas 5 .

As categorias analíticas emergiram por meio da pesquisa bibliográfica, trazendo à tona elementos para compreensão do ensino da EF na EJA (CARVALHO, 2009; 2011; CARVALHO; CAMARGO, 2019; COSTA, 2017).

A pesquisa bibliográfica foi utilizada para compreendermos, a partir da produção científica, as categorias analíticas EF e EJA, sendo reveladas e analisadas diante da produção.

Já o trabalho de campo procurou ser compreendido ao fundamentarmonos em Minayo, Deslandes e Gomes (2016), para além de um simples ambiente investigativo ligado às descobertas, visando não apenas conhecer, compreender e estudar o fenômeno, mas também criar possibilidades para que o conhecimento investigado desvele a realidade presente.

Desta pesquisa de campo, emergiram as categorias empíricas: Experiência Profissional; Formação Inicial; Organização do Conhecimento e Formação Continuada. No entanto, foi a categoria Organização do Conhecimento que revelou maior incidência a partir do contato com os professores de EF da rede municipal de ensino da Prefeitura do Ipojuca/PE.

A partir dessa categoria empírica, debruçamo-nos sobre as unidades de registro ${ }^{6}$ Metodologia de ensino e Realidade escolar, pois estas permearam, com maior evidência os resultados e discussão da pesquisa, as falas dos professores de EF que atuam na EJA, conforme apresentado no Quadro 1.

Quadro 1 - Indicadores para a análise de conteúdo

\begin{tabular}{|l|l|}
\hline \multicolumn{2}{|c|}{ Indicadores } \\
\hline Elemento central & O ensino da Educação Física na EJA \\
\hline Operacionalização & Processo de ensino-aprendizagem da Educação Física na EJA \\
\hline Categorias analíticas & Educação Física e EJA \\
\hline $\begin{array}{l}\text { Categoria empírica: } \\
\text { Organização do } \\
\text { conhecimento }\end{array}$ & Unidades de registros: Metodologia de ensino e Realidade escolar \\
\hline
\end{tabular}

Fonte: Autores.

\footnotetext{
5 "As primeiras são aquelas que retêm historicamente as relações sociais fundamentais e podem ser consideradas balizas para o conhecimento do objeto nos seus aspectos gerais. Elas mesmas comportam vários graus de abstração, generalização e de aproximação. As segundas são aquelas construídas com finalidade operacional, visando ao trabalho de campo (a fase empírica) ou a partir do trabalho de campo. Elas têm a propriedade de conseguir apreender as determinações e as especificidades que se expressam na realidade empírica" (MINAYO, 1998, p. 94).

6 "Unidade de registro é uma unidade de significação a ser codificada e corresponde ao menor segmento de conteúdo a ser considerado como unidade de base, visando à categorização, podendo ser de natureza e dimensões variadas" (BARDIN, 1988, p. 104-105).
} 


\section{RESULTADOS E DISCUSSÃO}

O ensino da EF na EJA em Ipojuca/PE teve início no ano de 2013 com a inserção do componente curricular na matriz regular de ensino da rede municipal.

Nessa rede de ensino não há, até o momento, documento curricular que oriente o ensino da EF na EJA, sendo subsidiado por elementos presentes no PCPE em EF para EJA (PERNAMBUCO, 2013a).

Para ministrar aulas na EJA, de acordo com os professores, foram utilizados diferentes procedimentos didático-metodológicos, a saber:

Bastantes aulas expositivas, com apresentação em PowerPoint. Vou discutindo com eles, trago vídeos. Muitas vezes, faço roda de conversas, faço debates acerca de algum tema e também com as práticas corporais (PROFESSORAA).

Eu procuro sempre, antes de tudo, começar com um texto ou com um debate. A partir do texto, ou um vídeo, eu começo perguntando: 'Você já fez isso?'. Aí, a partir dessa primeira, como eu posso dizer, colocação de ideias, eles começam um debate, a gente discute algumas coisas (PROFESSORA B).

Nós trazemos esse pessoal para trabalhar com palestras, a estrutura nos dá condição de trabalhar dessa forma. Fora o convencional, com aulas expositivas, visuais (PROFESSOR C).

Didaticamente falando, eu procuro sempre manter esse foco de explicar algo de maneira sucinta para que eles entendam, e também desenvolvam isso, consequentemente, numa parte prática (PROFESSOR D).

[...] a gente trabalha basicamente com vídeos, aulas expositivas, com a participação prática deles no desenrolar das aulas. Isso prende bastante a atenção deles. Alguns textos didáticos, mas não muitos, por conta da dificuldade que boa parte dos alunos têm de ler, porque eu trabalho com os quatro ciclos aqui, do fundamental, EJA I, EJA II, EJA III e EJA IV (PROFESSOR E).

[...] esse ano, eu resolvi quase que totalmente de forma teórica, com aulas expositivas, exibição de vídeos com temas tratados em cada bimestre (PROFESSOR F).

Eu trago muitos textos para meus alunos, muitos vídeos, filmes e algumas aulas que são práticas (PROFESSOR G).

A gente trabalha com aulas expositivas, utilização de recursos audiovisuais, pesquisa, roda de diálogos (PROFESSOR H).

Os procedimentos revelam a variedade de formas utilizadas no desenvolvimento das aulas de EF na EJA na rede municipal do Ipojuca. Os professores A, B, C, E, F, $\mathrm{G}$ e $\mathrm{H}$ apresentam mais de uma estratégia para mediar o conhecimento durante a unidade de ensino.

Há, a partir dos depoimentos dos professores, nuances de aproximações com estratégias de ensino presentes a partir de aulas do tipo expositiva, tendo a produção audiovisual, o texto didático e a roda de diálogo como caminhos possíveis para o ensino da EF.

Essa ação realizada pelos professores da rede municipal aproxima-se do que orienta o PCPE (PERNAMBUCO, 2013b), pois a sua organização orienta aos 
docentes o acesso aos conhecimentos da cultura corporal presentes na EF, visando fornecer contribuições teórico-metodológicas para as aulas de EF na EJA.

Libâneo (2017) considera importante que o processo didático esteja centrado na relação entre o ensino e a aprendizagem, que direciona para uma confrontação direta do aluno com a matéria sob a orientação do professor.

Esse processo acontece de modo orgânico e estruturado, havendo uma sintonia entre os elementos que compõem o ensino e a educação, com características e especificidades que possibilitam aproximações, devido à sua natureza e particularidade. Por outro lado, esses termos precisam ser melhor compreendidos, evitando a utilização destes como sinônimos.

A educação compreende processos formativos presentes na vida em sociedade, tendo características que não se restringem apenas à escola, pois é um processo marcado por um momento histórico, fruto de significados sociais e políticos almejados, possibilitando a transformação sucessiva no sentido histórico e no desenvolvimento da personalidade. Já o ensino é um processo intencional, sistemático e paulatino, responsável pelo desenvolvimento e transformação sucessivos das capacidades intelectuais dos estudantes, em direção ao domínio dos conhecimentos e habilidades, visando a sua aplicação (LIBÂNEO, 2017).

A educação e o ensino podem caminhar juntos para compreensão e reflexão das questões de natureza social, política, filosófica e pedagógica que incidem sobre a sociedade e, em especial, sobre a escola e a prática pedagógica dos professores, contribuindo com a tomada de decisão dos sujeitos, vislumbrando uma ação humana participativa, solidária e cidadã, realizada em parceria entre o professor e os estudantes.

Segundo Libâneo (2017), as ações conjuntas entre professores e alunos são imprescindíveis, possibilitando assimilar consciente e ativamente os conteúdos e os métodos, de forma criativa e nas diversas situações escolares e na vida prática.

Os professores A, B, E, G e H aproximam-se da postura metodológica que o autor argumenta, pois possibilitam a interação entre professor-aluno e a participação durante o processo de ensino-aprendizagem nas aulas._

Essa variedade de procedimentos, entretanto, tal como vemos nas falas dos professores $\mathrm{B}, \mathrm{C}, \mathrm{E}, \mathrm{F} \mathrm{e} \mathrm{H}$, apresenta uma contradição, ocorrendo uma ruptura da unidade teoria-prática, revelada na fragmentação dos procedimentos tratados nas aulas de EF na EJA.

É certo afirmar que as aulas de EF na EJA não precisam ter um formato definido, acabado e linear, pois é importante prestarmos atenção às trajetórias de vida dos estudantes, principalmente por eles terem, em geral, idade mais avançada que os estudantes do ensino regular, nos segmentos fundamental e médio. Mas essa centralidade de atividades expositivas, tratando de aspectos teóricos, pode estar gerando contrassensos, pois necessitamos compreender as representações que os estudantes trazem de suas trajetórias escolares para que não se repita o que já vivenciaram como experiência negativa em outros espaços educacionais (REIS; MOLINA NETO, 2014, p. 640). 
A EF tem muito a contribuir com a EJA, na medida em que reconhece a diversidade dos sujeitos, fornecendo elementos teórico-metodológicos para seu processo de tomada de decisão que se inicia na sala de aula, podendo ser extrapolado para a realidade de modo crítico e reflexivo.

As aulas de EF ministradas de maneira teórica podem se fazer presentes durante a prática pedagógica dos professores e dos estudantes da EJA, considerandose as características locais, especificidades e anseios dos estudantes. Coadunamos, porém, com o pensamento de Reis e Molina Neto (2014) quando apontam que as aulas de EF na EJA, quando ministradas apenas de maneira teórica, colaboram com o elitismo intelectual, havendo um dualismo entre corpo e mente, sendo o segundo responsável pelo intelecto, enquanto o "corpo" fica em segundo plano.

Apesar disso, os autores advertem para que se considere o contexto, o respeito para a realidade dos estudantes da EJA, pois a aula de EF nessa modalidade de ensino pode fazer uso de recursos audiovisuais e da produção textual como subsídios para a prática pedagógica, tal como sinaliza o estudo de Lisboa e Pires (2004), que apresenta contribuições para o uso da mídia, tal como a televisão, um veículo que pode se fazer presente nas aulas de EF.

Essa proposta aproxima-se das estratégias desenvolvidas pelos professores $A, E, F, G$ e H, que utilizam a produção audiovisual nas aulas de EF na EJA, visando contextualizar os conhecimentos abordados em sala de aula, tomando o recurso multimídia como aliado para a prática pedagógica.

Lisboa e Pires (2004) argumentam que, nas gerações mais recentes, a TV faz parte de sua realidade desde o nascimento, construindo percepções e representações do mundo à sua volta. $\mathrm{Na}$ atualidade, além da TV, os smartphones, tablets e as mídias digitais estão cada vez mais incorporados à rotina de vida da população, devido à sua aplicabilidade no âmbito do comércio e serviço, mobilidade urbana, segurança pública, saúde/bem-estar e educação.

A utilização de recursos tecnológicos nas aulas de EF na EJA, alinhada ao planejamento elaborado pelo professor, pode contribuir para o processo de ensinoaprendizagem, a começar por uma seleção, organização e sistematização do conhecimento em sintonia com a realidade dos estudantes e da prática pedagógica dos professores.

Além disso, o uso do texto didático é mais um recurso importante para os professores que ministram aulas na EJA, pois apresentam contribuições para a prática pedagógica, além de aproximar os estudantes dos conhecimentos da EF como uma nova possibilidade: a produção escrita.

Amaral (2014) investigou o uso do texto didático na prática pedagógica dos professores da rede estadual de ensino de Pernambuco, suas possibilidades, limites e contribuições para o processo de ensino-aprendizagem. Para o autor, o texto didático ainda é pouco difundido nas aulas de EF, apesar de produções emergentes na área.

Para ele, ainda há limites acerca da elaboração, que exige do professor um rigor técnico e científico a fim de que possa materializar os conhecimentos da EF ao longo da vida escolar. Há uma certa dificuldade por parte dos professores em 
dissertar sua experiência acumulada em formato digital, assim como através da produção escrita.

A produção de texto didático e dos recursos audiovisuais podem contribuir para o ensino da EF na EJA, possibilitando que os estudantes tenham acesso aos conhecimentos produzidos historicamente nesse componente curricular, de modo a fornecer elementos para seu processo de formação humana.

Em síntese, a metodologia de ensino engloba diferentes procedimentos didático-metodológicos, os quais orientam a contextualização do conhecimento, o confronto de saberes, a organização e reorganização do conhecimento em aulas e sínteses avaliativas.

Entretanto, a variedade metodológica de procedimentos não pode se dar apenas diante de estratégias, tendo como pano de fundo uma aula informativa e teórico-conceitual. Ela deve diversificar as formas, respeitando a diversidade dos sujeitos nessa modalidade, além de atentar para as experimentações e vivências corporais, o que não exime tais tipos de aula de teorias e conceitos, mas sendo fundamental que se deem para além da exposição oral do conhecimento.

Outra unidade de registro que emergiu ao longo da pesquisa de campo foi a realidade escolar, entendendo-a como a expressão do que de fato existe no chão da escola e na ação da prática pedagógica como condição dialética, dinâmica e que é influenciada(dora) nas/das relações que se desenvolvem na prática social e no âmbito escolar.

Carvalho e Borges (2010) concebem a realidade escolar como arcabouço que engloba práticas pedagógicas, cotidiano dos alunos, professores e funcionários dentro e fora das escolas, que refletem nos índices educacionais (aprovação e reprovação) e evasão escolar.

A realidade escolar, em nosso estudo, revelou informações acerca do contexto sociocultural, do processo de ensino-aprendizagem e prática pedagógica dos professores de EF que ministram aulas na EJA da rede municipal de ensino do Ipojuca.

[...] Tenho alguns materiais que eu já produzi, que eu ando com eles. Que eu levo para sala de aula, levo para escola, que não fico presa ao que tem disponível pra mim na escola (PROFESSORA A).

[..] Não adianta fazer um planejamento de primeiro mundo, com quadra, se a escola não tem essa realidade (PROFESSORA B).

Minha vivência na EJA, eu levo em conta muito o cotidiano do aluno da EJA, em particular a vivência dele regional aqui, de onde eu estou lotado, no Município. Levo em conta a vivência, o modo de vida deles, o que é mais interessante, para eles, de ser aprendido (PROFESSOR C).

Na minha realidade, a gente tenta trabalhar os conteúdos, seguindo o que a gente planeja durante o ano. [...] Até porque a realidade da EJA é uma realidade muito diferenciada das outras turmas (PROFESSOR D).

A escola tem uma estrutura relativamente boa para que a gente trabalhe as questões teóricas da Educação Física, sim. [...] Eu sinto falta de espaços e momentos para ter mais aulas práticas com eles, eu recebo cobrança de alguns com relação a isso (PROFESSOR E). 
[...] A lousa digital foi uma coisa que veio somar bastante, porque, como tem acesso à internet, a gente teve como trabalhar de maneira teórica, né? (PROFESSOR F).

[...] Quando eu vou planejar minhas aulas, eu levo em consideração não só o que a escola possui, mas também aquilo que eu possuo (PROFESSOR $\mathrm{G).}$

Alguns conteúdos facilitam essa aproximação. Por exemplo, ao abordar jogos é muito mais dinâmico, esse processo é mais integrado teoria e prática. [..] Outros conteúdos que a gente necessitaria de um espaço e de algumas ferramentas ou instrumentos para que pudesse acontecer, a gente tem que fazer através de imagens ou exemplos deles mesmos (PROFESSOR H).

Os professores comungam da ideia de que as aulas, o planejamento e a utilização de recursos metodológicos requerem uma aproximação com a realidade dos alunos, do contexto local, possibilitando um entrelaçamento do conhecimento historicamente construído na EF com a prática social dos estudantes da EJA.

Corroborando esse pensamento, os estudos de Haddad (2007), Machado e Rodrigues (2014) revelam avanços para o debate acerca da EJA, apresentando a urgência de refletir acerca dessa modalidade de educação de modo crítico, contribuindo para o debate sobre os rumos da prática pedagógica e das políticas públicas da EJA no Brasil, na expectativa de proposições que efetivem o direito a uma escolarização para todas as pessoas, independentemente da sua idade (HADDAD, 2007).

A materialização de propostas educativas faz-se com o reconhecimento dos sujeitos (estudantes e professores) enquanto seres dotados de conhecimentos e de potencialidades que necessitam ser considerados em ações que compreendam a EJA em consonância com a realidade sociocultural.

A EJA, sobretudo na última década, requer compreensão e análise atentas, pois apresenta caminhos mediante desafios pedagógicos para a prática docente, a partir do Plano Nacional de Educação (PNE) 2014-2024, especificamente, em sintonia com as metas 8,9 e 10 desse plano, que propõem ações significativas que incidem sobre a prática pedagógica e a formação de professores (MACHADO; RODRIGUES, 2014).

Tais metas buscam garantir direitos à educação presentes em outros dispositivos legais, efetivando o compromisso do poder público com a população brasileira (BRASIL, 2000, 2016, 2020a). Em relação à elevação dos níveis de escolaridade, temos enquanto metas: no mínimo, 12 anos de estudo no último ano de vigência desse Plano, para as populações do campo, da região de menor escolaridade no País; erradicar o analfabetismo absoluto e reduzir em $50 \%$ a taxa de analfabetismo funcional; oferecer, no mínimo, $25 \%$ das matrículas de educação de jovens e adultos, nos ensinos fundamental e médio, na forma integrada à educação profissional (BRASIL, 2014a).

A compreensão das questões que envolvem as políticas públicas e a educação enquanto direito humano universal da EJA é imprescindível para a prática pedagógica dos professores, pois ao serem refletidas e aprofundadas por estudiosos 
(HADDAD; DI PIERRO, 2015; ARROYO, 2017; PAIVA; HADDAD; SOARES, 2019; SOARES; PEDROSO, 2016), fornecem elementos para entender a realidade em que se encontram inseridos os sujeitos (estudantes e professores).

Os professores $\mathrm{B}$ e C trazem à tona que a realidade é ponto de partida para elaboração, desenvolvimento e materialização do planejamento. Freire (2010) orienta que ensinar exige a apreensão da realidade, pois, enquanto professor, é preciso estar atento às diversas dimensões que permeiam a prática para assegurar a atuação profissional.

Para o autor, apreender a realidade permite conhecer o lócus em que está circunscrita, suas as características, seus limites, pois conhecendo-a há a possibilidade de transformá-la, intervindo, recriando, vislumbrando outra realidade.

Essa aproximação da realidade escolar encontra-se presente no documento no PCPE (PERNAMBUCO, 2013b), possibilitando que professores elaborem, planejem e desenvolvam aulas segundo as características do estudante da EJA, que tem particularidades e anseios, podendo, numa maior incidência que o ensino regular, apresentar limitações físicas, psicossociais e afetivas em função de idade mais avançada de alguns estudantes, ainda que nos dias atuais seja crescente a presença de alunos mais jovens nessa modalidade.

Neste sentido, é necessária a compreensão acerca da realidade da nova conjuntura que vem sendo expressa na EJA: um processo de "rejuvenescimento" dos estudantes dessa modalidade de ensino (RATIER et al., 2011). Segundo os autores, o quantitativo de jovens na EJA do Ensino Fundamental é preocupante, pois já somam aproximadamente $20 \%$ dos matriculados, no período 2004 e 2010, entre 15 a 17 anos.

Os dados do Censo Escolar do ano de 2013 a 2020 indicam um aumento de matrículas de estudantes jovens na EJA. No entanto, esse aumento em períodos recentes permanece com pequenas oscilações (Tabela 1).

Tabela 1 - Dados do Censo Escolar do ano de 2013 a 2020.

\begin{tabular}{ccccc}
\hline Ano & Total & $\begin{array}{c}\text { Percentual de } \\
\text { queda }\end{array}$ & $\begin{array}{c}\text { Estudantes entre 15 e 29 } \\
\text { anos }\end{array}$ & $\begin{array}{c}\text { Percentual de } \\
\text { matrículas }\end{array}$ \\
\hline 2013 & 3.830 .207 & -------- & 2.368 .511 & $61,83 \%$ \\
2014 & 3.653 .530 & $9,53 \%$ & 2.270 .845 & $62,15 \%$ \\
2015 & 3.491 .869 & $9,55 \%$ & 2.208 .767 & $63,25 \%$ \\
2016 & 3.482 .174 & $9,97 \%$ & 2.247 .225 & $64,53 \%$ \\
2017 & 3.598 .716 & ------- & $2.246,047$ & $68,37 \%$ \\
2018 & 3.545 .988 & $1,5 \%$ & 2.205 .604 & $62,2 \%$ \\
2019 & 3.273 .668 & $7,7 \%$ & 2.622 .149 & $62,2 \%$ \\
2020 & 3.002 .749 & 8,3 & 1.852 .945 & $61,3 \%$ \\
\hline
\end{tabular}

Fonte: Instituto Nacional de Estudos e Pesquisas Educacionais Anísio Teixeira - INEP Dados sobre Censo Escolar - 2013 a 2020.

A partir desses dados do Censo Escolar, observa-se um acréscimo significativo de matrículas de jovens na EJA, revelando um processo de juvenilização que vem 
sendo cada vez mais comum nessa modalidade de educação, evidenciado a partir da literatura (ALCANTARA, 2016; DUARTE, 2015; ARROYO, 2017; LEMOS, 2017;) e dos documentos oficiais (BRASIL, 2011; 2012; 2013, 2014b; 2015, 2016, 2017b, 2018, 2019, 2020b).

A mudança no perfil do estudante da EJA envolve uma gama de informações que resulta desde ausência de políticas públicas concretas que assegurem a manutenção e a permanência dos sujeitos no sistema de ensino regular, como também a saída dos alunos de maior faixa etária (adultos e idosos) da modalidade, transformando o perfil e a dinâmica do cotidiano da EJA (DUARTE, 2015).

A presença da juventude, em especial, na escola precisa ser refletida e compreendida pelos professores que ministram aulas nessa modalidade da educação, pois o jovem traz consigo características e especificidades próprias que precisam ser consideradas durante a prática pedagógica, buscando aproximar os conhecimentos produzidos no interior das escolas com a realidade sociocultural dos sujeitos.

Freire (2010) argumenta que, ao criar condições para que essa realidade seja alterada, é necessário um entendimento de quais são os sujeitos da aprendizagem, seus anseios, e aspirações; que haja entendimento e respeito ao saber do educando.

No que diz respeito à EJA, o processo de ensino-aprendizagem pode ocorrer a partir da dinamicidade, contemporaneidade e da tomada de decisões dos professores durante as aulas. O estudo de Freire (2010) e o PCPE (PERNAMBUCO, 2013b) fornecem elementos para compreender que a realidade da EJA difere do ensino regular pela estrutura, organização e diversidade de sujeitos.

Outro dado que emergiu sobre a realidade que os professores $\mathrm{E}, \mathrm{Fe} \mathrm{H}$ relataram foi a dificuldade de trabalhar os conhecimentos da EF por meio da aula teórica, do tipo expositiva, para exemplificar os conteúdos. Essa postura metodológica gerou, inclusive, descontentamento dos estudantes e do professor $\mathrm{E}$, o que fez com que os estudantes solicitassem mais experimentação corporal durante as aulas.

Reis e Molina Neto (2014) propõem uma compreensão da realidade escolar: escuta dos estudantes e dos seus anseios para, então, elaboração das aulas, na materialização da prática pedagógica. Para os autores, as aulas de EF na EJA podem, sim, ser ministradas de maneira teórica, desde que atendam aos anseios da comunidade escolar e as expectativas dos estudantes sejam também consideradas na elaboração do planejamento escolar, tornando-se mais um espaço para o compartilhamento de conhecimento da EF.

O respeito à realidade escolar, na particularidade que cada professor utiliza para ministrar aulas na EJA, precisa ser efetivo. Essa realidade precisa ser considerada, refletida e compreendida, possibilitando o entendimento daquilo que é possível durante a prática pedagógica. Além disso, é importante ouvir os anseios dos estudantes da EJA, dialogando sobre os conhecimentos a serem ministrados, visando coletivamente decidirem os rumos do ensino para o período letivo.

Com o professor, percebemos a necessidade de escutarmos as solicitações dos estudantes, analisarmos e tomarmos decisões que possibilitem, quando possível, 
sua implementação na prática pedagógica. Essa ação permite aos sujeitos o acesso aos conhecimentos da EF sob diferentes formas. Tais conhecimentos podem ser vivenciados na escola, na quadra ou, ainda, extrapolar os muros da escola, a partir de aulas teóricas ou teórico-práticas.

A realidade escolar, ao fazer parte do processo de reflexão do professor, da prática pedagógica, do seu planejamento e avaliação, aproxima os conhecimentos de ensino do contexto sociocultural dos estudantes, oportunizando o compartilhamento de conhecimentos que possam trazer sentidos e significados para os sujeitos da aprendizagem.

A realidade escolar revela caminhos para o ensino dos professores de EF que ministram aulas no contexto da EJA, sendo imprescindível considerar a diversidade metodológica e o perfil da aula, pautados tanto nos aspectos conceituais expositivos como em experiências corporais. Conhecer, usar e qualificar os recursos materiais disponíveis, a infraestrutura e a localidade onde estão inseridas as unidades de ensino contribui para articular os objetivos, planejamento e avaliação dos conhecimentos da EF na EJA.

\section{CONSIDERAÇÕES FINAIS}

O ensino da EF no contexto da EJA, presente na rede municipal de ensino da Prefeitura do Ipojuca/PE, revelou a partir de falas dos professores que a realidade escolar e a metodologia de ensino foram compreendidas ao serem ministradas aulas nessa modalidade da educação.

Os professores apresentaram, por meio das suas falas, uma diversidade de metodologias para socialização do conhecimento na EJA, apresentando pelo menos mais de uma estratégia de ensino. Essa variedade de estratégia de ensino revela a busca dos professores por caminhos teórico-metodológicos para o ensino da EF no contexto da EJA.

Quanto à variedade procedimental, é preciso levar em consideração a diversidade do tempo e espaço da escola na EJA e, mais ainda, dos sujeitos, já que podem conviver numa mesma sala de aula pessoas com grandes diferenças etárias, favorecendo a todos a possibilidade de experimentar corporalmente os conteúdos da EF.

A realidade escolar que emergiu nas falas dos professores foi considerada como ponto de partida para elaboração e sistematização dos conhecimentos que reconhecem o contexto sociocultural dos estudantes da EJA como indispensáveis para o ensino da EF.

Foi possível identificar, em falas de professores, que a falta de infraestrutura/ materiais nas instituições escolares, ausência de quadras poliesportivas, ou mesmo um ambiente apropriado às práticas corporais limitam as aulas na EJA a mera exposição teórica. Os docentes reconhecem que a EF na EJA não deve ser tratada apenas com aulas teóricas - até porque há reivindicações de alunos quanto a isso e sim que haja uma relação teórico-prática. 
A realidade escolar norteou objetivos, planejamentos e avaliações que foram desenvolvidos ao longo do ano letivo, sendo considerada a infraestrutura das unidades de ensino, o material pedagógico do qual a escola dispõe e o contexto sociocultural dos estudantes para o ensino da EF na EJA.

Em síntese, reconhecemos que cabe à Educação Física Escolar assegurar o acesso aos bens culturais, ao conhecimento produzido historicamente no que concerne às práticas corporais e que, na escola, as variedades metodológicas devam estar na reflexão e ação pedagógicas que potencializam o conhecimento junto ao estudante da EJA, de forma a garantir suas aprendizagens.

\section{REFERÊNCIAS}

ALCANTARA, Marivane Silva de. Juvenilização da Educação de Jovens e Adultos em Abaetetuba: representações sociais e projeto de vida escolar. 2016. 155 f. Dissertação (Mestrado em Educação) - Universidade do Estado do Pará, Belém, 2016.

AMARAL, Lucas Vieira do. Textos didáticos na prática pedagógica do professor de Educação Física da rede estadual de ensino de Pernambuco: possibilidades, limites e contribuições. 2014. 163f. Dissertação (Mestrado em Educação Física) - Universidade de Pernambuco, Escola Superior de Educação Física, Recife, 2014.

ARROYO, Miguel González. Passageiros da noite: do trabalho para a EJA: itinerários pelo direito a uma vida justa. Petropólis: Vozes, 2017.

BARDIN, Laurence. Análise de conteúdo. Lisboa: Edições, 1988, 2011.

BEISIEGEL, Celso de Rui. Estado e Educação popular: um estudo sobre a educação de adultos. São Paulo: Liber, 2004.

BRASIL. Constituição da República Federativa do Brasil, de 5 de outubro de. Disponível em:https://www2.senado.leg.br/bdsf/bitstream/handle/id/566968/CF88_EC105_livro.pdf. Acesso em: 14 jun.2021

BRASIL. LDB- Lei de diretrizes e bases da educação nacional. Brasília: Câmara dos Deputados, Edições Câmara, 2017a.

BRASIL. Lei no 13.005, de 25 de junho de 2014. Aprova o Plano Nacional de Educação - PNE e dá outras providências. Diário Oficial da União, Brasília, DF, 26 jun.2014a. Disponível em: http://www.planalto.gov.br/ccivil_03/_ato2011-2014/2014/lei//13005.htm Acesso em: 14 jun.2021.

BRASIL. Conselho Nacional de Educação. Parecer CNE/CEB n¹1/2000 e Resolução CNE/ CEB n¹1/2000. Diretrizes Curriculares para a Educação de Jovens e Adultos. Brasília: MEC. Disponível em: http://portal.mec.gov.br/cne/arquivos/pdf/PCB11_2000.pdf . Acesso em: 15 jun.2021

BRASIL. Instituto Nacional de Estudos e Pesquisas Educacionais Anísio Teixeira. Censo da Educação Básica: Resumo Técnico da Educação Básica. Disponível em: http://portal.inep. gov.br/informacao-da-publicacao/-/asset_publisher/6JYlsGMAMkW1/document/id/6993007 . Acesso em: 13 jun. 2020. 
BRASIL. Instituto Nacional de Estudos e Pesquisas Educacionais Anísio Teixeira. Censo da Educação Básica: Resumo Técnico da Educação Básica. Disponível em: http://portal.inep. gov.br/informacao-da-publicacao/-/asset publisher/6JYIsGMAMkW1/document/id/6874720 . Acesso em: 13 jun. 2021.

BRASIL. Instituto Nacional de Estudos e Pesquisas Educacionais Anísio Teixeira. Censo da Educação Básica: Resumo Técnico da Educação Básica. Disponível em: http://portal.inep. gov.br/informacao-da-publicacao/-/asset publisher/6JYlsGMAMkW1/document/id/6386080 . Acesso em: 13 jun. 2021

BRASIL. Instituto Nacional de Estudos e Pesquisas Educacionais Anísio Teixeira. Censo da Educação Básica: Resumo Técnico da Educação Básica. Disponível em: https://download. inep.gov.br/publicacoes/institucionais/estatisticas e indicadores/resumo tecnico censo da educacao basica 2017.pdf . Acesso em: 13 jun. 2021.

BRASIL. Instituto Nacional de Estudos e Pesquisas Educacionais Anísio Teixeira. Censo da Educação Básica: Notas estatísticas, 2016.Disponível em: https://download.inep.gov.br/ educacao basica/censo escolar/notas estatisticas/2017/notas estatisticas censo escolar da educacao basica 2016.pdf. Acesso em: 13 jun. 2021

BRASIL. Instituto Nacional de Estudos e Pesquisas Educacionais Anísio Teixeira. Censo da Educação Básica: Notas estatísticas, 2017b. Disponível em: www.inep.gov.br/educacao basica/censo escolar/notas estatisticas/2017/notas estatisticas do censo escolar 2015 matriculas.pdf acesso em: 13 jun. 2021.

BRASIL. Instituto Nacional de Estudos e Pesquisas Educacionais Anísio Teixeira. Censo da Educação Básica: Notas estatísticas, 2014b.Disponível em: https://download.inep.gov. br/educacao basica/censo escolar/notas estatisticas/2017/notas estatisticas do censo escolar 2014\%20final.pdf . Acesso em: 13 jun.2021

BRASIL. Instituto Nacional de Estudos e Pesquisas Educacionais Anísio Teixeira. Censo da Educação Básica: Resumo técnico, 2013a.Disponível em: https://download.inep.gov. br/educacao basica/censo escolar/resumos tecnicos/resumo tecnico censo educacao basica 2013.pdf . Acesso em: 13 jun.2021

BRASIL. Instituto Nacional de Estudos e Pesquisas Educacionais Anísio Teixeira. Censo da Educação Básica: Resumo técnico. Disponível em https://download.inep.gov.br/educacao basica/censo escolar/resumos tecnicos/resumo tecnico censo educacao basica 2012. pdf . Acesso em: 13 jun.2021.

BRASIL. Instituto Nacional de Estudos e Pesquisas Educacionais Anísio Teixeira. Censo da Educação Básica: Resumo técnico. Disponível em: https://download.inep.gov.br/educacao basica/censo_escolar/resumos tecnicos/resumo_tecnico_censo_educacao_basica_2011. pdf . Acesso em: 13 jun.2021.

BRASIL. Ministério da Educação. Secretaria de Educação Básica. Diretoria de Currículos e Educação Integral Diretrizes Curriculares Nacionais Gerais da Educação Básica. Brasília: 2013b. 562p.

CARVALHO, Ricardo Luis Cavalcanti de; BORGES, Sam Thiago Pereira. Realidade Escolar - Um relato etnográfico. CAOS. Revista Eletrônica de Ciências Sociais, v. 1, p. 110-121, 2010.

CARVALHO, Rosa Malena. Educação Física Escolar e Educação de Jovens e Adultos. In: CONGRESSO BRASILEIRO DE CIÊNCIA DO ESPORTE(CBCE) 16; CONGRESSO INTERNACIONAL DE CIÊNCIAS DO ESPORTE, 2009; (CONICE), Salvador-BA. [Anais eletrônicos...]. Salvador: CBCE, 2009. Disponível em: http://congressos.cbce.org.br/index. php/conbrace2009/XVI/paper/view/671/574. Acesso em: 12 jun.2021. 
CARVALHO, Rosa Malena. Entre a Educação Física Escolar e a Educação de Jovens e Adultos. In: CARVALHO, Rosa Malena (org.). Educação Física escolar na educação de jovens e adultos. Curitiba: CRV, 2011. p. 11-18.

CARVALHO, Rosa Malena; CAMARGO, Maria Cecília. Formação de professores em Educação Física e a Educação de Jovens e Adultos. Movimento (Porto Alegre), v. 25, p. 1-13, 2019. DOI: https://doi.org/10.22456/1982-8918.85233

COSTA, Maria da Conceição dos Santos. Trabalho docente e Formação em Educação Física na Educação de Jovens e Adultos no Município de Belém-PA. 2017. 232 f. Tese (Doutorado em Educação). - Universidade Federal do Pará, Instituto de Ciência da Educação, Belém, 2017.

DUARTE, Marcelo Laranjeira. "Juvenilização na EJA": Reflexões sobre juventude(s) e escola no Município de Angra dos Reis. Dissertação (Mestrado). - Universidade do Estado do Rio de Janeiro, Duque de Caxias, 2015.

FRANCHI, Silvester; GÜNTHER, Maria Cecília Camargo. Juvenilização da EJA: repercussões na Educação Física. Motrivivência, v. 30, n. 53, p. 209-225, abr. 2018.

FREIRE, Paulo. Pedagogia da Autonomia: saberes necessários à prática educativa. 31 . ed. São Paulo: Paz e Terra, 2010.

GIL, Antonio Carlos. Métodos e técnicas de pesquisa social. 6. ed. São Paulo:Atlas, 2008.

GÜNTHER, Maria Cecília Camargo. O direito à educação física na educação de jovens e adultos. Revista Brasileira de Ciências do Esporte, v. 36, n. 2, p. 400-412, abr./jun.2014.

HABERMAS, Jürgen. Dialética e hermenêutica. Porto Alegre: L\&PM, 1987.

HADDAD, Sérgio. Por uma nova cultura na Educação de Jovens e Adultos, um balanço de experiências de poder local. In: REUNIÃO ANUAL DA ANPED: 30 anos de pesquisa e compromisso social, 30., 2007. [Anais eletronicos...]. Rio de Janeiro: Anped, 2007. Disponível em: https://www.anped.org.br/biblioteca/item/por-uma-nova-cultura-na-educacaode-jovens-e-adultos-um-balanco-de-experiencias-de Acesso em: 12 jun.2021.

HADDAD, Sérgio; DI PIERRO, Maria Clara. Escolarização de jovens e adultos. Revista Brasileira de Educação, n. 14, p. 108-130, 2000.

HADDAD, Sergio; DI PIERRO, Maria Clara. Transformações nas políticas de educação de jovens e adultos no Brasil no iníci do terceiro milênio: uma análise das agendas nacional e internacional. Caderno do CEDES , v. 39, p. 197-217, 2015.

LEMOS, Amanda Guerra de, "Despeja na EJA": reflexões acerca da migração perversa de jovens para o PEJA no município do Rio de Janeiro. 2017. 113 f. Dissertação (Mestrado em Educação) - Universidade Federal do Estado do Rio de Janeiro, Rio de Janeiro, 2017.

LIBÂNEO, José Carlos. Didática [Livro eletrônico]. São Paulo: Cortez, 2017.

LISBOA, Mariana Mendonça; PIRES, Giovani De Lorenz. Televisão, representações sociais e cultura de movimento: tecendo reflexões de uma trama no contexto da infância. Motrivivência, ano 16, n. 23, p.119-141, dez. 2004.

MACHADO, Maria Margarida; RODRIGUES, Maria Emília de Castro. A EJA na próxima década e a prática pedagógica docente. Retratos da Escola , v. 8, p. 383-395. jul./dez.2014 
MARTINS, Jacqueline Cristina Jesus. Educação física, currículo cultural e a educação de jovens e adultos: novas possibilidades. 2019. 381.f. Dissertação ( Mestrado em Formação, Currículo e Prática pedagógica) - Faculdade de Educação. Universidade de São Paulo, 2019.

MINAYO, Maria Cecília de Souza. O desafio do conhecimento: Pesquisa qualitativa em Saúde. São Paulo; Rio de Janeiro: Hucitec; Abrasco, 1998.

MINAYO, Maria Cecília de Souza; DESLANDES, Suely Ferreira; GOMES, Romeu. Pesquisa Social: teoria, método e criatividade em saúde. Petrópolis: Vozes, 2016.

NEGREIROS, Izis Carolina Miranda de. Propostas curriculares estaduais de Educação Física para a EJA: uma análise da relação conteúdo-organização do trabalho pedagógico. Monografia (Graduação em Educação Física) - Escola Superior de Educação Física, Universidade de Pernambuco, 2013.

OLIVEIRA, João Paulo dos Santos; SOUSA, Fábio Cunha; MELO, Maíra da Rocha. Produção do conhecimento em Educação Física no chão da escola através do estágio supervisionado: relato de experiência com estudantes da Educação com Jovens e Adultos. Motrivivencia, v. 27, p. 247-261, set. 2015.

PAIVA, Jane; HADDAD, Sérgio; SOARES, Leôncio José Gomes. Pesquisa em educação de jovens e adultos: memórias e ações na constituição do direito à educação para todos. Revista brasileira de educação, v. 24, p. 10-25, 2019.

PAIVA, Vanilda. História da educação popular no Brasil. 6. ed. São Paulo: Loyola/ Ibrades, 2002.

PERNAMBUCO.(Estado). Secretaria de Educação e Esportes. Parâmetros Curriculares para Educação Básica: Parâmetros Curriculares de Educação Física - Educação de Jovens de Adultos.Recife, 2013a.

PERNAMBUCO. (Estado). Secretaria de Educação. Parâmetros Curriculares para Educação Básica. Parâmetros Curriculares de Educação Física - Ensino Fundamental e Médio. Recife, 2013b.

RATIER, Rodrigo et al. Por que jovens de 15 a 17 anos estão na EJA? Revista Nova Escola, 01 de Ago. 2011.Disponível em: https://novaescola.org.br/conteudo/2882/por-quejovens-de-15-a-17-anos-estao-na-eja . Acesso em: 14 de jun. 2021

REIS, José Antônio Padilha dos. As trajetórias de vida dos estudantes-trabalhadores da educação de jovens e adultos: os significados da educação física: um estudo em uma escola da Rede Municipal de Ensino de Porto Alegre. 2011. 216 f. Dissertação (Mestrado em Ciências do Movimento Humano) - Escola de Educação Física, Fisioterapia e Dança, Universidade Federal do Rio Grande do Sul. Porto Alegre, Brasil- RS.

REIS, José Antônio Padilha dos; MOLINA NETO, Vicente. "Pensei que estava na aula de ciência" ou os significados da educação física na educação de jovens e adultos. Pensar a Prática (Online), v. 17, p. 636-650, jul./set.2014. DOI: https://doi.org/10.5216/rpp. $\underline{\mathrm{v} 17 \mathrm{i} 3.26145}$

SOARES, Leôncio José Gomes; PEDROSO, Ana Paula Ferreira. Formação de educadores na educação de jovens e adultos (eja): alinhavando contextos e tecendo possibilidades. Educação em revista (UFMG), v. 32, p. 251-268, out./dez. 2016. DOI: https://doi. org/10.1590/0102-4698161277 
STRELHOW, Thyeles Borcarte. Breve história sobre a educação de jovens e adultos no Brasil. Revista HistedBR On-line, v. 10, n. 38, p. 49-59, jun. 2010. DOI: https://doi. org/10.20396/rho.v10i38.8639689 
Abstract: The purpose of this study was to analyze Physical Education teaching in the context of EJA (Youth and Adult Education) by the Municipal School Network of Ipojuca, PE, based on teachers' statements. It was a qualitative study conducted through semi-structured interviews with eight subjects and the hermeneutic dialectic method using the theme: categorical content for data assessments. It found that teachers used different teaching methodologies in their lessons, which showed clear evidence of a need for practices to make body experimentation as a central element, in addition to taking into consideration school reality, infrastructure to propose classes, projects and seminars, along with planning and evaluation of knowledge to guide their practices.

Keywords: Education. Adult. Adolescent. Methodology.

Resumen: El estudio tuvo como objetivo analizar la enseñanza de Educación Física en el contexto de la EJA (Educación de Jóvenes y Adultos) en la red municipal de educación de la municipalidad de Ipojuca/PE, a partir de las intervenciones de los profesores. Se trata de un estudio cualitativo que se apoya en el método hermenéutico-dialéctico, realizado con ocho profesores, a través de entrevistas semiestructuradas, utilizando la técnica de análisis de contenido categorial por tema para el análisis de los datos. Se concluye que los profesores utilizaron diferentes metodologías de enseñanza para impartir sus clases y que existe la necesidad de prácticas que permitan la experimentación corporal como centralidad, además de considerar la realidad de la escuela y la infraestructura para proponer clases, proyectos y seminarios a partir de objetivos, planificación y evaluación de los conocimientos que orientan sus prácticas.

Palabras clave: Educación. Adulto. Adolescente. Metodología. 


\section{LICENÇA DE USO}

Este é um artigo publicado em acesso aberto (Open Access) sob a licença Creative Commons Atribuição 4.0 Internacional (CC BY 4.0), que permite uso, distribuição e reprodução em qualquer meio, desde que o trabalho original seja corretamente citado. Mais informações em: https://creativecommons.org/licenses/by/4.0

\section{CONFLITO DE INTERESSES}

Os autores declararam que não existe nenhum conflito de interesses neste trabalho.

\section{CONTRIBUIÇÕES AUTORAIS}

Sérgio Henrique Noblat de Andrade Júnior: Revisão de literatura, efetivação das entrevistas semiestruturadas com os professores participantes do estudo e pela sistematização do processo de análise de conteúdo.

Agostinho da Silva Rosas: Confrontar dos resultados iniciais da pesquisa com os dados da realidade, consubstanciando as inferências, contribuindo também com a conclusão do estudo.

Ana Rita Lorenzini: Contribuições teórico-metodológicas, resultados e discussões, além de proceder à revisão de Língua Portuguesa.

Lívia Tenório Brasileiro: Contribuições teórico-metodológicas dos resultados e discussão, a partir das categorias metodologia de ensino e realidade escolar que subsidiaram as discussões do estudo, além de realizar o procedimento de revisão de Língua Portuguesa

Marcílio Barbosa Mendonça de Souza Júnior: Orientar o processo de coleta e análise de dados, além de contribuir com a qualificação dos resultados, discussões e conclusão do estudo.

Marcelo Soares Tavares de Melo: Organização e tratamento dos dados, além de contribuir na fase dos resultados e discussão do estudo.

\section{FINANCIAMENTO}

O presente trabalho foi realizado com apoio da Coordenação de Aperfeiçoamento de Pessoal de Nível Superior - Brasil (CAPES) - Código de Financiamento 001. "This study was financed in part by the Coordenação de Aperfeiçoamento de Pessoal de Nível Superior - Brasil (CAPES) - Finance Code 001"

\section{ÉTICA DE PESQUISA}

O projeto de pesquisa foi encaminhado e aprovado pelo Complexo Hospitalar Universitário Oswaldo Cruz (Huoc) /Pronto Socorro Cardiológico Universitário de Pernambuco (Procape), da Universidade De Pernambuco (Upe), protocolo 93198417.8.0000.5192

\section{COMO REFERENCIAR}

ANDRADE JUNIOR, Sergio Henrique Noblat de; ROSAS, Agostinho da Silva; LORENZINI, Ana Rita; BRASILEIRO, Lívia Tenorio; SOUZA JÚNIOR, Marcílio Barbosa Mendonça de; MELO, Marcelo Soares Tavares de. O ensino da educação física na EJA: uma análise a partir de falas dos professores. Movimento (Porto 
Alegre), v.27, p.e27074, jan./dez. 2021. Disponível em: https://seer.ufrgs.br/ Movimento/article/view/112519. Acesso em: [dia] [mês abreviado]. [ano]. DOI: https://doi.org/10.22456/1982-8918.112519

\section{RESPONSABILIDADE EDITORIAL}

Alex Branco Fraga*, Elisandro Schultz Wittizorecki*, Ivone Job*, Lisandra Silva*, Mauro Myskiw*, Raquel da Silveira*

*Universidade Federal do Rio Grande do Sul, Escola de Educação Física, Fisioterapia e Dança, Porto Alegre, RS, Brasil. 